\title{
Subperiosteal chin augmentation with hyaluronic acid filler in patients with a small chin
}

\author{
Kyoungjin Kang, MD, PhD, FKCCS ${ }^{1}$, Choongyee Chai, $\mathrm{MS}^{2}$ \\ ${ }^{1}$ Seoul Cosmetic Surgery Clinic, Busan, Rep. of Korea, ${ }^{2}$ Korean College of Cosmetic Surgery, Busan, Rep. of Korea
}

\begin{abstract}
Background: For correction of small chin, surgical genioplasty, allograft implantation, and injectable filler have been widely used. Among these, the injectable fillers is a simple, non-invasive procedure that has minimal downtime and low risk of complications. It has been commonly injected at intradermal, subdermal, submuscular and supraperiosteal layer. However, common complications such as nodules, bumps, lumps, migration, asymmetry, overcorrection, and chin ptosis frequently happened.

Objective: The main objective of this study was injecting filler into sub-periosteal layer in a small chin and evaluated its effect and incidence of complications.

Methods: A total of 14 subjects aged between 33 and 64 years had been performed Elravie ${ }^{\circledR}$ hyaluronic acid filler injection subperiosteally and Medytoxin ${ }^{\circledR}$ as a botulinum toxin treatment intramuscularly. Morphological change were observed through the photos. Changes of proportion of lower $1 / 3$ face, Modified Legan's angle, and open gap distance of lips were measured. Follow-up patient satisfaction surveys were conducted from 2 to 3 weeks.

Results: Proportion of lower face was significantly changed that the ratio of upper and middle $1 / 3$ were decreased $(5.26 \%, 3.85 \%)$ and the ratio of lower $1 / 3$ was increased (8.33\%). Modified Legan's angle was significantly decreased (37.4 $\pm 16.5 \%)$. Open gap distance between lips was decreased $(66.2 \pm 17.9 \%)$ and dry mouth was significantly decreased. Lower facial contour was changed from round shape to elliptical shape and mouth looked smaller and less protruded. Upper lip was everted, but lower lip was inverted. Perioral wrinkles, labio-mandibular folds, and mental dimples were significantly decreased. There was no significant incidence of common complications including chin ptosis.

Conclusion: Subperiosteal filler injection is easy, safe and effective in improvement of small chin and interestingly, showed additional beneficial effects such as improvement of dry mouth, lips contour, and perioral wrinkles.

Level of Evidence: IV
\end{abstract}

Keywords: subperiosteal chin augmentation; injectable filler; chin ptosis; dry mouth

\section{Introduction}

Patients with a small chin have typical features, such as a wide and short face, protruded mouth, chin drooping, exposed teeth due to incomplete lip closure, bunching and pouting, and wrinkles and dimpling of the skin [1]. In addition, many patients may experience dryness of the mouth because of incomplete mouth closure during sleep.

Sliding genioplasty, autologous or allograft implantation, and filler injection have been performed as representative treatment modalities for the small chin [2]. Among these, the filler procedure is commonly used for chin augmentation because of

Received August 10 2017, Revised November 21 2017, Accepted November 212017

Corresponding author: Kyoungjin Kang, Seoul Cosmetic Surgery Clinic, 10th floor, New Nampo B/D \#4, Gudeok-ro 34 Beon-gil, Jung-gu, Busan 48954,

Rep. of Korea

Tel: 82-51-247-7776, Fax: 82-51-248-7765, E-mail: mdkjkang@hanmail.net

This is an Open Access article distributed under the terms of the Creative Commons Attribution Non-Commercial License (http://creativecommons.org/licenses/by-nc/4.0), which permits unrestricted non-commercial use, distribution, and reproduction in any medium, provided the original work is properly cited.

Copyright (c) 2017. Korean Society of Korean Cosmetic Surgery (KSKCS) Korean College of Cosmetic Surgery (KCCS). 
the minimal down time and fewer complications. Moreover, the recent trend of non-invasive cosmetic surgery, rather than the perfection and persistence of the procedure's treatment effects, may have contributed to its popularity.

Usually, fillers are injected into the intradermal, subdermal, and supraperiosteal layers to correct small chins [3] and both sharp needles and blunt cannulas were inserted at three points of the entry site [4]. Apart from common complications, such as swelling, redness, tenderness, bruising, filler migration, bumps or lumps, asymmetry, irregularities, and nodules, relatively serious complications, such as chin drooping have also occurred frequently [5]. Among these, the mechanism of chin drooping is as follows: when the filler is injected into the intradermal, subdermal, and supraperiosteal layer in a patient who has a small and flat chin, chin drooping can occur more easily because of decreased skeletal support for the chin soft tissue. This is caused by increased soft tissue weight from the injected filler.

This hypothesis is supported by some studies that reported that facial sagging was caused not only by soft tissue aging, but also by skeletal deformities [6,7], and that it can be improved by the modification of volume restoration from the bone and soft tissues [8]. Thus, a small chin can easily lead to incomplete mouth closure and teeth exposure when the mentalis muscle is relaxed. Therefore, most patients with a small chin tend to excessively contract the mentalis muscle to close their mouth. This is the main cause of bunching, pouting, and soft tissue deformities, such as chin wrinkles, mentalis dimpling [9], and loss of the submental fat pad. Further, the opening of the mouth during sleep due to mentalis relaxation can lead to drying of the mouth.

Finally, the authors suggest that subperiosteal filler injection is the fundamental solution to the above complications. It is expected to produce not only chin augmentation, but also decrease the gap between the lips by increasing skeletal support. Additionally, the authors used a sharp needle and six to eight points of entry for the exact and even placement of the filler. Botulinum toxin treatment was also administered to prevent filler migration postoperatively.

To evaluate the effect of the subperiosteal filler augmentation, the change in the lower one-third of the facial proportion, modified Legan's angle, gap between the lips, and the morphological changes of the chin, lips, and perioral area were evaluated from the pre- and postoperative photographs of the patients.

\section{Materials and methods}

\section{Patients and follow-up}

Filler chin augmentation was performed for 14 patients with a small chin who visited the Seoul Cosmetic Surgery Clinic between March and June 2017. The effect of the augmentation was assessed 2-3 weeks after the procedure.

\section{Preoperative marking}

Three vertical lines (a, b and c) were first marked, two horizontal lines (e and f) were made separately after touching the Superior and inferior borders of the mandible with the fingertips. The intersections of the three vertical and two horizontal lines were used as the entry points (i.e., 1, 2, 3, 4, 5 and 6). Subsequently, the naturally expanded semi-circular lateral areas were located while pinching the soft tissue of the medial commissure with the thumb and index finger. A black-colored outline, like a school bus track, was made for the chin augmentation. The labiomental depression was marked and its entry

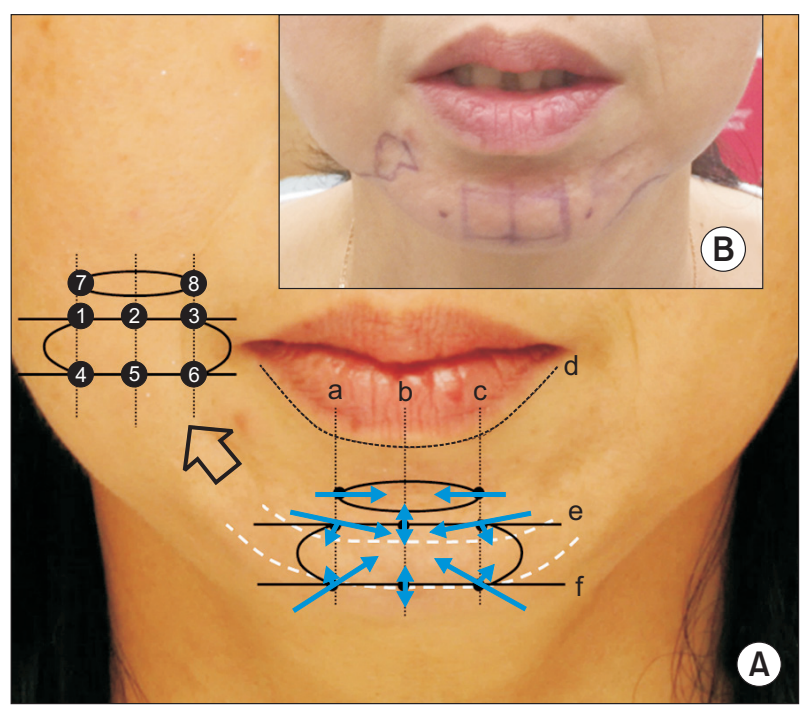

Fig. 1. Preoperative markings for sequential augmentation of filler injection (SAFI). (A) Schematic drawing for determination of injection area and entry site, (B) Practical marking for filler injection in the state of the mentalis muscle in repose. The numbers (i.e., 1 to 8) represent the entry sites. Upper/lower white dotted lines indicate surface marking lines from superior/inferior border of mandible respectively. (a) and (c) Two vertical black-colored dotted lines indicate the boundary line between the medial and lateral part of vermillion, (b) A vertical black-colored dotted line indicates the center of medial part of the vermillion, (d) A black-colored dotted line indicates lower vermillion border, and (e) Transverse line on the skin corresponds to muco-buccal fold in oral cavity, and (f) Transverse line for inferior boder of mandible, Upper and lower blue arrows indicate the direction of needle insertion and bevel's orientation. 
points were numbers 7 and 8 (Fig. 1).

\section{Anesthesia}

$0.1 \mathrm{ml}$ of $2 \%$ lidocaine solution mixed with epinephrine $(1: 100,000)$ was injected into the eight entry sites from the periosteum to the skin, retrogradely.

\section{Filler and botulinum toxin injection}

In the first session of the filler injection, an average of $2.43 \pm 0.73$ $\mathrm{ml}$ of Elravie ${ }^{\circledR}$ Premier Ultravolume-L (hyaluronic acid 23mg/ $\mathrm{ml}, 0.3 \%$ lidocaine, Humedix Co., Ltd., Anyang, Republic of Korea) were injected. Where needed, a second session was performed at least 2-3 weeks later. Subperiosteal bolus injection of the filler was performed through the entry sites in the order of 1 to 6 . Thereafter, the filler was injected into the labiomental depression through the other entry sites (7 and 8) (Fig. 1A). A 23 gauge sharp needle was inserted into the 2 -cc syringe of the filler. The needle was approached towards the central zone of the medial commissure of the lower lip, touching the bone directly, and the filler was slowly injected after checking intravascular injection by withdrawing the plunger. At any entry site, the bevel of the needle can be oriented upwards, downwards or lateralwards according to the purpose of the injection (projection, lengthening, or widening of the chin). Medytoxin ${ }^{\circledR}$ (10 units/0.5 cc of Botulinum toxin; Meditox Inc., Cheongju, Republic of Korea) was injected into the mentalis muscle to prevent postoperative migration of the filler. A $3 \mathrm{M}$ tape was used to fix the chin for 3 days postoperatively, and cold compression was applied for 2 days.

\section{Measurement}

\section{Proportion of the lower one-third of the face}

Changes in the length of each zone (I, II, and III) were measured from the pre- and postoperative photographs and the change of the pre- and postoperative ratio was also calculated (Fig. 2A).

\section{Modified Legan's angle}

To evaluate the anterior projection of the soft tissues, we measured the modified Legan's angle [10], which is the angle between the line from the nasion to the subnasale and the line from the pogonion to the subnasale (Fig. 2B).

\section{The gap between the lips}

The gap between the upper and lower lips when the mentalis muscle is relaxed was measured before and after the procedure using a ruler (Fig. 2C).

\section{Morphological changes of the chin, lips, and perioral area}

From the pre- and postoperative photographs, contour changes of the chin, lips, nasolabial folds, and perioral wrinkles, when the corner of the mouth is elevated, were also observed.

\section{Dry mouth}

Two to three weeks after the procedure, patients who had subjective symptoms such as dryness of the mouth prior to the procedure were examined to ascertain whether the symptom had improved. We assumed the perception of the symptom
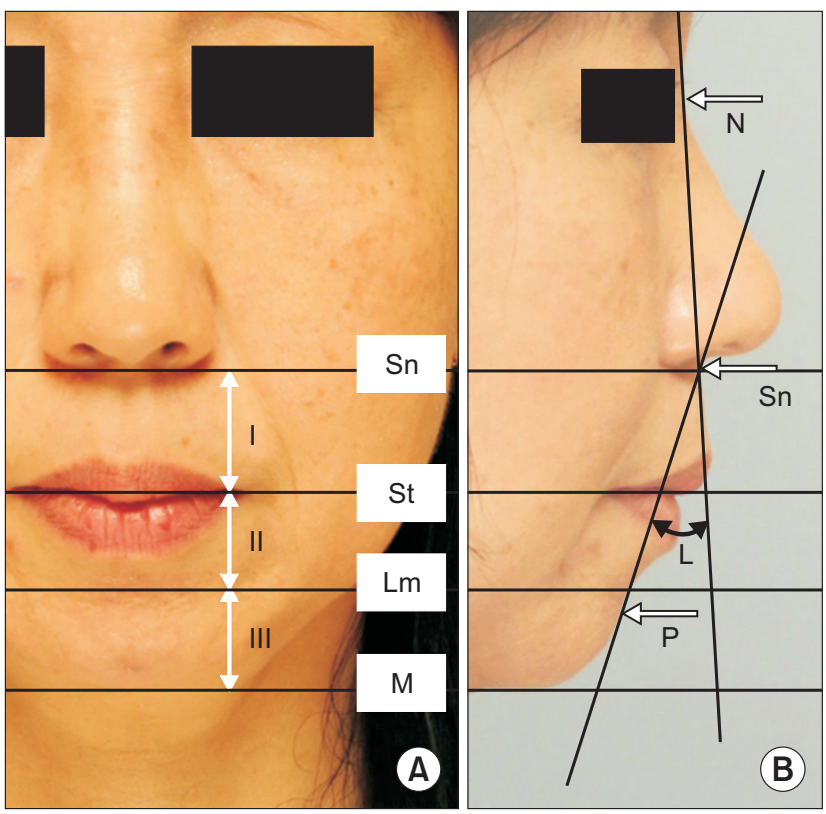

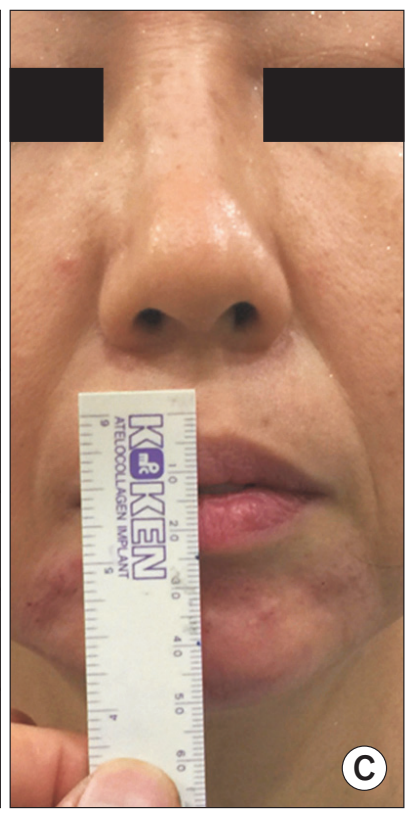

Fig. 2. Measurements of lower face proportion, modified Legan's angle and open gap between upper and lower lips. (A) Frontal view of facial proportion, (B) Lateral view of Legan's angle, (C) Frontal view of measurement of gap distance in the status of mentalis muscle in repose. Zone I, II, and III represent the upper, middle and lower $1 / 3$ of the lower face, Sn, subnalsale; St, stomion; Lm, labiomental crease; $\mathrm{Mt}$, menton; $\mathrm{N}$, nasion; $\mathrm{P}$, pogonion; L, Legan's angle. 
before the procedure to be $100 \%$; thus, the perception of the symptom after the procedure was recorded as percentages.

\section{Results}

\section{Statistical analysis}

\section{Amount of Botulinum toxin and hyaluronic acid filler used} Ten units of Medytoxin ${ }^{\circledR}$ and Elravie $^{\circledR}$ (mean, $2.43 \pm 0.73 \mathrm{ml}$ ) Premier Ultravolume-L were injected. For chin projection, more amount of filler was injected into 1, 2, and 3 entry sites than into 4, 5, 6 entry sites (Table 1).

\section{Proportion of the lower one-third of the face}

The total length of the lower face was increased $(\mathrm{p}=0.003)$. Among the zones, only the increase in the length of zone III was statistically significant $(\mathrm{p}<0.05)$. The ratio of the length of each zone to the total length of the lower face showed significant changes in zone I and III ( $\mathrm{p}=0.001$ and $\mathrm{p}=0.000$, respectively). However, there was no statistically significant change in zone II (Table 2, 3).

\section{Modified Legan's angle}

As shown in the photograph, the decrease in Legan's angle indicated an increase in the anterior projection of the soft tis- sues of the small chin. As seen in the figures, this angle was significantly reduced in all patients, after the procedure, by an average of $37.1 \pm 16.71 \%$ (Table 4 ).

\section{The gap between the lips}

The gap between the lips significantly reduced in all cases, after the procedure (Table 4). In this study, the rate of decrease in the gap between the lips after the procedure was $66.2 \pm 17.89 \%$.

\section{Dry mouth}

Preoperatively, eight of the patients had subjective symptom of dry mouth when they woke up in the morning. Among them, one patient had no improvement $(0 \%)$ after the procedure, however, the seven other patients experienced a significant decrease in the symptom $(77.14 \pm 20.59 \%)$ (Table 4$)$.

\section{Complications}

Swelling and pressure pain occurred in all cases but disappeared within one week. Bleeding and bruising at the entry sites of the lidocaine injection occurred in two patients. Moreover, asymmetry occurred, which was not caused by over-correction or hypo-correction but was caused by the difference in soft tissue thickness, which had been reduced by excessive mentalis muscle contraction before the procedure. The subjective opinions of patients 'my chin became too big after the procedure',

Table 1. Amount of Hyaluronic acid filler and botulinum toxin used for chin and prejowl area

\begin{tabular}{|c|c|c|c|c|c|c|c|c|c|c|c|c|c|}
\hline \multirow{3}{*}{$\begin{array}{l}\text { Number } \\
\text { of cases } \\
\text { (n) }\end{array}$} & \multirow{3}{*}{ Sex } & \multirow{3}{*}{ Age } & \multirow{3}{*}{$\begin{array}{l}\text { Medytoxin }^{\circ} \\
\text { (units) }^{\mathrm{a})}\end{array}$} & \multicolumn{10}{|c|}{ Elravie $^{\circledR}$ premier ultravolume-L hyaluronic acid filler $\left.{ }^{b}\right)$} \\
\hline & & & & \multirow{2}{*}{$\begin{array}{c}\text { Total } \\
\text { amount } \\
(\mathrm{ml})\end{array}$} & \multicolumn{7}{|c|}{ Injected amount to each entry site $(\mathrm{ml})$} & \multicolumn{2}{|c|}{$\begin{array}{c}\text { Injected } \\
\text { amount to prejowl }\end{array}$} \\
\hline & & & & & 1 & 2 & 3 & 4 & 5 & 6 & $7 \& 8$ & Right & Left \\
\hline 1 & $\mathrm{~F}$ & 60 & 10 & 2.1 & 0.3 & 0.2 & 0.4 & 0.4 & 0.2 & 0.4 & 0.2 & & \\
\hline 2 & $\mathrm{~F}$ & 33 & 10 & 2.5 & 0.3 & 0.1 & 0.6 & 0.3 & 0.1 & 0.5 & & & 0.6 \\
\hline 3 & M & 40 & 10 & 2 & 0.4 & 0.2 & 0.4 & 0.4 & 0.2 & 0.4 & & & \\
\hline 4 & $\mathrm{~F}$ & 34 & 10 & 2 & 0.4 & 0.3 & 0.4 & 0.4 & 0.1 & 0.4 & & & \\
\hline 5 & $\mathrm{~F}$ & 61 & 10 & 2 & 0.4 & 0.3 & 0.4 & 0.4 & 0.1 & 0.4 & & & \\
\hline 6 & $\mathrm{~F}$ & 48 & 10 & 2 & 0.5 & 0.2 & 0.3 & 0.4 & 0.3 & 0.3 & & & \\
\hline 7 & $\mathrm{~F}$ & 61 & 10 & 2.25 & 0.4 & 0.4 & 0.4 & 0.2 & 0.3 & 0.25 & 0.3 & & \\
\hline 8 & $\mathrm{~F}$ & 64 & 10 & 1.2 & 0.3 & 0.2 & 0.3 & 0.2 & 0 & 0.2 & & & \\
\hline 9 & $\mathrm{~F}$ & 44 & 10 & 4 & 0.6 & 0.6 & 0.6 & 0.4 & 0.4 & 0.4 & 1 & & \\
\hline 10 & $\mathrm{~F}$ & 52 & 10 & 3.2 & 0.5 & 0.3 & 0.7 & 0.7 & 0.5 & 0.5 & & & \\
\hline 11 & $\mathrm{~F}$ & 61 & 10 & 3 & 0.4 & 0.2 & 0.4 & 0.4 & 0.2 & 0.4 & 1 & & \\
\hline 12 & $\mathrm{~F}$ & 60 & 10 & 2 & 0.3 & 0.3 & 0.4 & 0.3 & 0.2 & 0.5 & & & \\
\hline 13 & $\mathrm{~F}$ & 48 & 10 & 3.4 & 0.6 & 0.2 & 0.6 & 0.5 & 0.2 & 0.5 & 0.2 & 0.2 & 0.4 \\
\hline 14 & $\mathrm{~F}$ & 63 & 10 & 2.3 & 0.4 & 0.2 & 0.4 & 0.4 & 0.2 & 0.4 & 0.3 & & \\
\hline $\mathrm{AVG}^{\mathrm{c})}$ & & 52.07 & 10 & 2.43 & 0.41 & 0.26 & 0.45 & 0.39 & 0.21 & 0.40 & 0.5 & & \\
\hline $\mathrm{SD}^{\mathrm{d})}$ & & 10.96 & 0 & 0.73 & 0.10 & 0.12 & 0.12 & 0.12 & 0.13 & 0.09 & 0.39 & & \\
\hline
\end{tabular}

${ }^{\text {a) }}$ Botulinum toxin, ${ }^{\text {b) }}$ Hyaluronic acid filler, ${ }^{\text {c) }} \mathrm{AVG}$, average; ${ }^{\mathrm{d})} \mathrm{SD}$, standard deviation. 
Table 2. Change of proportion in lower face

\begin{tabular}{|c|c|c|c|c|c|c|c|c|c|c|c|c|c|c|c|c|}
\hline \multirow{3}{*}{$\begin{array}{c}\text { Number } \\
\text { Of cases } \\
\text { (n) }\end{array}$} & \multirow{3}{*}{ Sex } & \multirow{3}{*}{ Age } & \multicolumn{14}{|c|}{ Change of facial proportion } \\
\hline & & & \multicolumn{4}{|c|}{ Length of Before (mm) } & \multicolumn{3}{|c|}{ Ratio of Before (\%) } & \multicolumn{4}{|c|}{ Length of After (mm) } & \multicolumn{3}{|c|}{ Ratio of After (\%) $)^{d)}$} \\
\hline & & & $\mathrm{I}^{\mathrm{a})}$ & II $^{\text {a) }}$ & III $^{\text {a) }}$ & Total $^{\text {b) }}$ & I/Total & II/Total & III/Total & $\mathbf{I}^{\text {a) }}$ & II $^{\text {a) }}$ & III $^{\text {a) }}$ & Total $^{\text {b) }}$ & I/Total & II/Total & III/Total \\
\hline 1 & $\mathrm{~F}$ & 60 & 20 & 14.5 & 21.5 & 56 & 35.7 & 25.9 & 38.4 & 20 & 13.5 & 22.5 & 56 & 35.7 & 24.1 & 40.2 \\
\hline 2 & $\mathrm{~F}$ & 33 & 16.5 & 12 & 18.9 & 47.4 & 34.8 & 25.3 & 39.9 & 16 & 11.4 & 20 & 47.4 & 33.8 & 24.1 & 42.2 \\
\hline 3 & $\mathrm{M}$ & 40 & 20 & 15.7 & 17 & 52.7 & 38 & 29.8 & 32.3 & 20 & 15.7 & 17 & 52.7 & 38 & 29.8 & 32.3 \\
\hline 4 & $\mathrm{~F}$ & 34 & 17.7 & 12.5 & 15.5 & 45.7 & 38.7 & 27.4 & 33.9 & 17.7 & 12.5 & 17.5 & 47.7 & 37.1 & 26.2 & 36.7 \\
\hline 5 & $\mathrm{~F}$ & 61 & 16.7 & 10 & 22.8 & 49.5 & 33.7 & 20.2 & 46.1 & 16.7 & 10 & 23.5 & 50.2 & 33.3 & 19.9 & 46.8 \\
\hline 6 & $\mathrm{~F}$ & 48 & 22.3 & 18 & 20 & 60.3 & 37 & 29.9 & 33.2 & 22.3 & 18 & 22 & 62.3 & 35.8 & 28.9 & 35.3 \\
\hline 7 & $\mathrm{~F}$ & 61 & 21.9 & 13 & 17.5 & 52.4 & 41.8 & 24.8 & 33.4 & 20.5 & 13 & 19.7 & 53.2 & 38.5 & 24.4 & 37 \\
\hline 8 & $\mathrm{~F}$ & 64 & 19 & 13.4 & 17.3 & 49.7 & 38.2 & 27 & 34.8 & 19 & 13.4 & 20 & 52.4 & 36.3 & 25.6 & 38.2 \\
\hline 9 & $\mathrm{~F}$ & 44 & 20 & 13 & 18 & 51 & 39.2 & 25.5 & 35.3 & 20 & 15.3 & 22 & 57.3 & 34.9 & 26.7 & 38.4 \\
\hline 10 & $\mathrm{~F}$ & 52 & 15.7 & 12.2 & 14.3 & 42.2 & 37.2 & 28.9 & 33.9 & 15.7 & 12.2 & 14.3 & 42.2 & 37.2 & 28.9 & 33.9 \\
\hline 11 & $\mathrm{~F}$ & 61 & 14 & 9 & 14 & 37 & 37.8 & 24.3 & 37.8 & 14 & 10 & 17 & 41 & 34.1 & 24.4 & 41.5 \\
\hline 12 & $\mathrm{~F}$ & 60 & 20.5 & 14.3 & 19 & 53.8 & 38.1 & 26.6 & 35.3 & 20.5 & 13 & 22 & 55.5 & 36.9 & 23.4 & 39.6 \\
\hline 13 & $\mathrm{~F}$ & 48 & 21 & 13 & 16 & 50 & 42 & 26 & 32 & 21 & 13 & 20 & 54 & 38.9 & 24.1 & 37 \\
\hline 14 & $\mathrm{~F}$ & 63 & 21.5 & 13.5 & 21.5 & 56.5 & 38.1 & 23.9 & 38.1 & 21.5 & 13 & 24 & 58.5 & 36.8 & 22.2 & 41 \\
\hline $\mathrm{AVG}^{\mathrm{e})}$ & & 52.07 & 19.1 & 13.2 & 18.1 & 50.3 & 37.9 & 26.1 & 36 & 18.9 & 13.1 & 20.1 & 52.2 & 36.2 & 25.2 & 38.6 \\
\hline $\mathrm{SD}^{\mathrm{f})}$ & & 10.96 & 2.54 & 2.21 & 2.7 & 5.99 & 2.28 & 2.54 & 3.78 & 2.49 & 2.13 & 2.82 & 6.01 & 1.74 & 2.73 & 3.72 \\
\hline
\end{tabular}

${ }^{\mathrm{a})}$ I, length of upper $1 / 3$; II, length of meddle $1 / 3$, and III, length of lower $1 / 3$; ${ }^{\text {b) }}$ Total=whole length of lower face $=\mathrm{I}+\mathrm{II}+\mathrm{III}$. ${ }^{\mathrm{c}}$ Ratio of before $(\%)$ : Ratio of before length of I or II or III to total before length of lower face=I or II or III /Total X100. ${ }^{\text {d) }}$ Ratio of after (\%): Ratio of after length of I or II or III to total after length of lower face=I or II or III /Total $\times 100 .{ }^{\mathrm{e})} \mathrm{AVG}$, average; ${ }^{\mathrm{f})} \mathrm{SD}$, standard deviation.

Table 3. Statistical analysis of proportional change in lower $1 / 3$ face from the raw data of Table 2

\begin{tabular}{lccc}
\hline \multirow{2}{*}{ Zone } & \multicolumn{2}{c}{ Change of facial proportion $(\mathbf{m m})$} & \multirow{2}{*}{$\mathbf{p}^{\text {a) }}$} \\
\cline { 2 - 3 } & \multicolumn{1}{c}{ Before } & After & \\
\hline I & $19.06 \pm 2.54$ & $18.92 \pm 2.49$ & 0.213 \\
II & $13.15 \pm 2.21$ & $13.14 \pm 2.13$ & 0.976 \\
III & $18.09 \pm 2.70$ & $20.11 \pm 2.82$ & 0.000 \\
Total & $50.30 \pm 5.99$ & $52.17 \pm 6.01$ & 0.003 \\
\hline \multirow{2}{*}{ Zone } & Zone's ratios of each zone to whole lower face $(\%)^{\mathbf{b})}$ & \multirow{2}{*}{$\mathbf{p}^{\text {a) }}$} \\
\cline { 2 - 3 } & Before & After & 0.001 \\
\hline I & $37.9 \pm 2.28$ & $36.2 \pm 1.74$ & 0.026 \\
II & $26.1 \pm 2.54$ & $25.2 \pm 2.73$ & 0.000 \\
III & $36.0 \pm 3.78$ & $38.6 \pm 22.2$ & \\
Total & 100 & 100 & \\
\hline
\end{tabular}

${ }^{a)}$ Paired t-test. ${ }^{\text {b) }}$ When the whole length of lower face is considered as $100 \%$, the average length's ratios of each zone.

were noted as overcorrection. Apart from this, there are no significant complications which have been reported by other researchers (Table 5).

\section{Morphological analysis}

\section{Shape of chin}

The chin was projected anteriorly and lengthened inferiorly and the labiomental crease moved superiorly due to increased skeletal support by the subperiosteal augmentation. Lengthening of the lower one-third of the face by chin augmentation significantly contributed to the change in the facial contour from round to elliptical (Fig. 3). Mental dimpling was immediately improved, although the filler was injected into the subperiosteal layer, and it was corrected with the combination of the botulinum toxin treatment (Fig. 4A, B).

\section{Shape of the mouth and lips}

Despite the eversion of the upper lip and shortening of the philtrum, the mouth looked small and less protruded (Fig. 3A, B). The lower lip was inverted and volumized, projected anteriorly, and rotated counterclockwise (Fig. 4C, D). These were due to the increased skeletal support by the chin augmentation.

The preoperative sagging appearance of the upper lip was improved by the shortened distance between the subnasale and the vermillion border of the upper lip. It was because of the need, to close mouth due to the decreased gap distance, was reduced (Fig. 3, 4).

\section{Change of perioral animation}

Before the procedure, the corner of the mouth was superolateral and perioral wrinkles, chin wrinkles, labiomandibular folds, 
Table 4. Change of modified Legan's angle, open gap distance between lips, and change of dry mouth

\begin{tabular}{|c|c|c|c|c|c|c|c|c|c|c|c|}
\hline $\begin{array}{c}\text { Number } \\
\text { Of cases (n) }\end{array}$ & Sex & Age & \multicolumn{3}{|c|}{ Modified Legan's angle $\left(^{\circ}\right)$} & \multicolumn{3}{|c|}{ Open gap distance (mm) } & \multicolumn{3}{|c|}{$\begin{array}{l}\text { Change of dry mouth as a } \\
\text { subjective symptom (\%) }\end{array}$} \\
\hline 1 & $\mathrm{~F}$ & 60 & 8 & 3 & 62.5 & 7.5 & 2.5 & 66.7 & 100 & 20 & 80 \\
\hline 3 & M & 40 & 11 & 8 & 27.3 & 2 & 0.5 & 75 & 0 & 0 & - \\
\hline 4 & $\mathrm{~F}$ & 34 & 24.5 & 19.5 & 20.4 & 2 & 0.5 & 75 & 0 & 0 & - \\
\hline 7 & $\mathrm{~F}$ & 61 & 21.7 & 16.2 & 25.3 & 3 & 0 & 100 & 0 & 0 & - \\
\hline 8 & $\mathrm{~F}$ & 64 & 6 & 3.5 & 41.7 & 5 & 2 & 60 & 100 & 0 & 100 \\
\hline 9 & $\mathrm{~F}$ & 44 & 24 & 19 & 20.8 & 7 & 4 & 42.9 & 0 & 0 & - \\
\hline 10 & F & 52 & 15.5 & 8.5 & 45.2 & 7 & 2.5 & 64.3 & 100 & 50 & 50 \\
\hline $\mathrm{AVG}^{\mathrm{c})}$ & & 52.1 & 14 & 9.59 & 37.1 & 5.54 & 2.18 & 66.2 & & & 77.14 \\
\hline $\mathrm{SD}^{\mathrm{d})}$ & & 11 & 6.561 & 6.04 & 16.71 & 2.41 & 1.59 & 17.87 & & & 20.59 \\
\hline
\end{tabular}

${ }^{a)}$ The change of subject symptom of dry mouth after the procedure if considering that dry mouth symptom felt before the procedure is $100 \%$. ${ }^{\text {b) }} \mathrm{RR}$ : Reduction ratio (\%)=(After $\times 100 /$ Before $)-100 .{ }^{\mathrm{c}}$ AVG, average; ${ }^{\mathrm{d})} \mathrm{SD}$, standard deviation.

Table 5. Possible complications and incidence from filler augmentation

\begin{tabular}{lclc}
\hline \multicolumn{1}{c}{ Complications } & Incidence (\%) & \multicolumn{1}{c}{ Complications } & Incidence (\%) $^{\text {a) }}$ \\
\hline Swelling/Pressure Pain & $14 / 14(100)$ & Lumps/ Bumps & $0 / 14(0)$ \\
Bleeding/Bruising & $2 / 14(14)$ & Infection /Inflammation & $0 / 14(0)$ \\
Asymmetry due to uneven surface & $2 / 14(14)$ & Nodules & $0 / 14(0)$ \\
Overcorrection & $2 / 14(14)$ & Vascular occlusion & $0 / 14(0)$ \\
Migration & $0 / 14(0)$ & Chin drooping & $0 / 14(0)$ \\
\hline
\end{tabular}

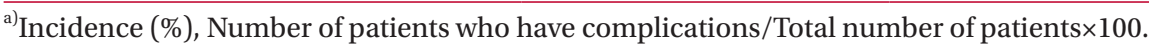

and the mental dimple were obvious when the corner of the mouth was elevated strongly (Fig. 5A, C) due to the combined contraction of the mentalis and risorius muscles. However, after the chin augmentation, the wrinkles and the folds were noticeably softened and shortened. The mental dimple was also corrected (Fig. 5B, D). This effect was caused the hypo-contraction of mentalis muscle, which was induced by subperiosteal filler augmentation.

\section{Discussion}

The injectable filler has been very popularly used to improve the lower facial contour with the correction of a small chin [4]. Although filler augmentation has been considered as an easy procedure, complications such as nodules, bumps, lumps, filler migration, asymmetry, and chin ptosis have frequently occurred when the filler is injected into the subdermal, intramus- cular, and submuscular layers, as shown in Fig. 6. Moreover, the incidence of complication is known to depend on the type, placement, and amount of the injected filler and the skill of the physician who performs the procedure. Because of this, the authors obtained some notable results by injecting the filler into the subperiosteal layer, which has not been commonly used for chin augmentation.

After subperiosteal augmentation, the small chin and contour of the lower face were notably improved. Bunching and pouting with a mental dimple, perioral wrinkles, and labio-mandibular folds immediately disappeared (Fig. 3). The gap between the lips was considerably decreased in all cases and almost all of the patients had great satisfaction with the easy closing of the mouth, and some patients had significant improvement of the early morning dry mouth (Table 4). Moreover, common complications were almost prevented or showed a very low incidence (Table 5). 

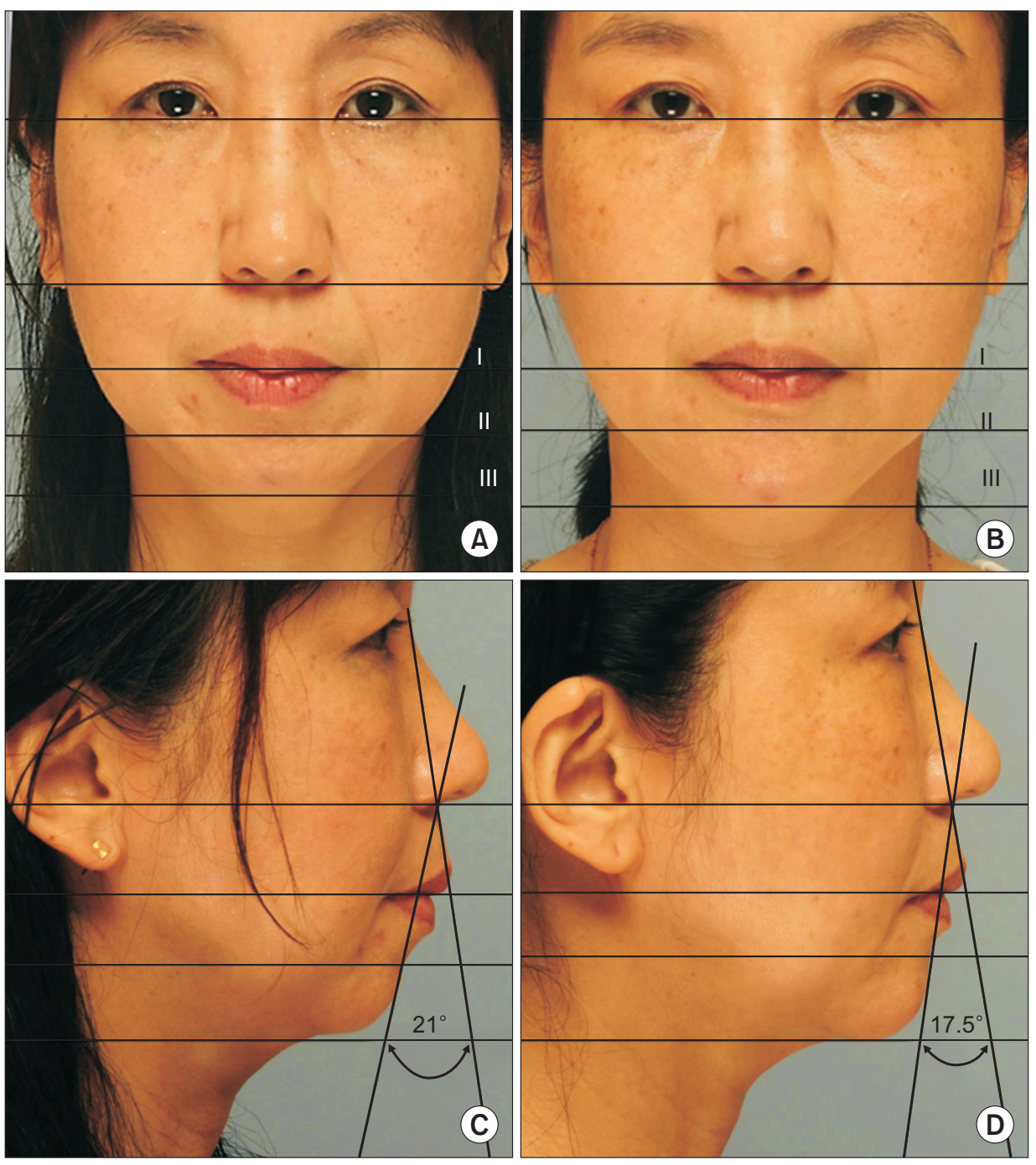

Fig. 3. Immediate changes of lips after chin augmentation in status of mentalis muscle on animation. Filler was injected into a 48-year-old woman who had a small chin (13th case from Table 1 and 2). Air jet ${ }^{\circledR}$ indirect infusion system (Union medical Co. Ltd, Republic of Korea) was also applied only to the fronto-temporoparietal areas for non-invasive face lifting.

Moreover, these morphological effects were strongly supported by the statistical analysis, which is as follows: the length of the lower one-third from the lower border of the face was increased and its proportional ratio to the lower face was also increased. It supported the change of contour in the lower face from round with a sagging appearance to elliptical with a lifted appearance (Table 3). The modified Legan's angle was significantly decreased in all cases. It strongly supported the anterior projection of the small chin, and eventually, the mouth looked smaller and less protruding. The decreased gap between the lips was due to increased skeletal support by the chin augmentation (Table 4). The augmentation resolved the mental dimple with bunching and pouting and prevented perioral animation (Fig. 4, 5). From these results, it was confirmed that there was a close correlation between the statistical measurements and the morphological analysis.
The morphological change in the length of the middle onethird was not obvious and there was also no statistically significant change in the length of the middle one-third. This was due to the inversion and anterior projection of the lower lip and also due to the influence of the decrease in the length of the upper lip caused by the decrease in the gap between the lips (Fig. 3, 4).

The reason for the decrease of the upper one-third was because the gap between the lips was markedly reduced by the change of the lower and middle one-third, and the need to contract the orbicular oris muscle in order to close the mouth was reduced.

The authors would like to describe the mechanism as below. First, we need to understand the basic concepts of the size and shape of the facial bones and the skeletal support of the soft tissues surrounding them. In other words, small and flat bones provide poor skeletal support to the surrounding soft tissues, 

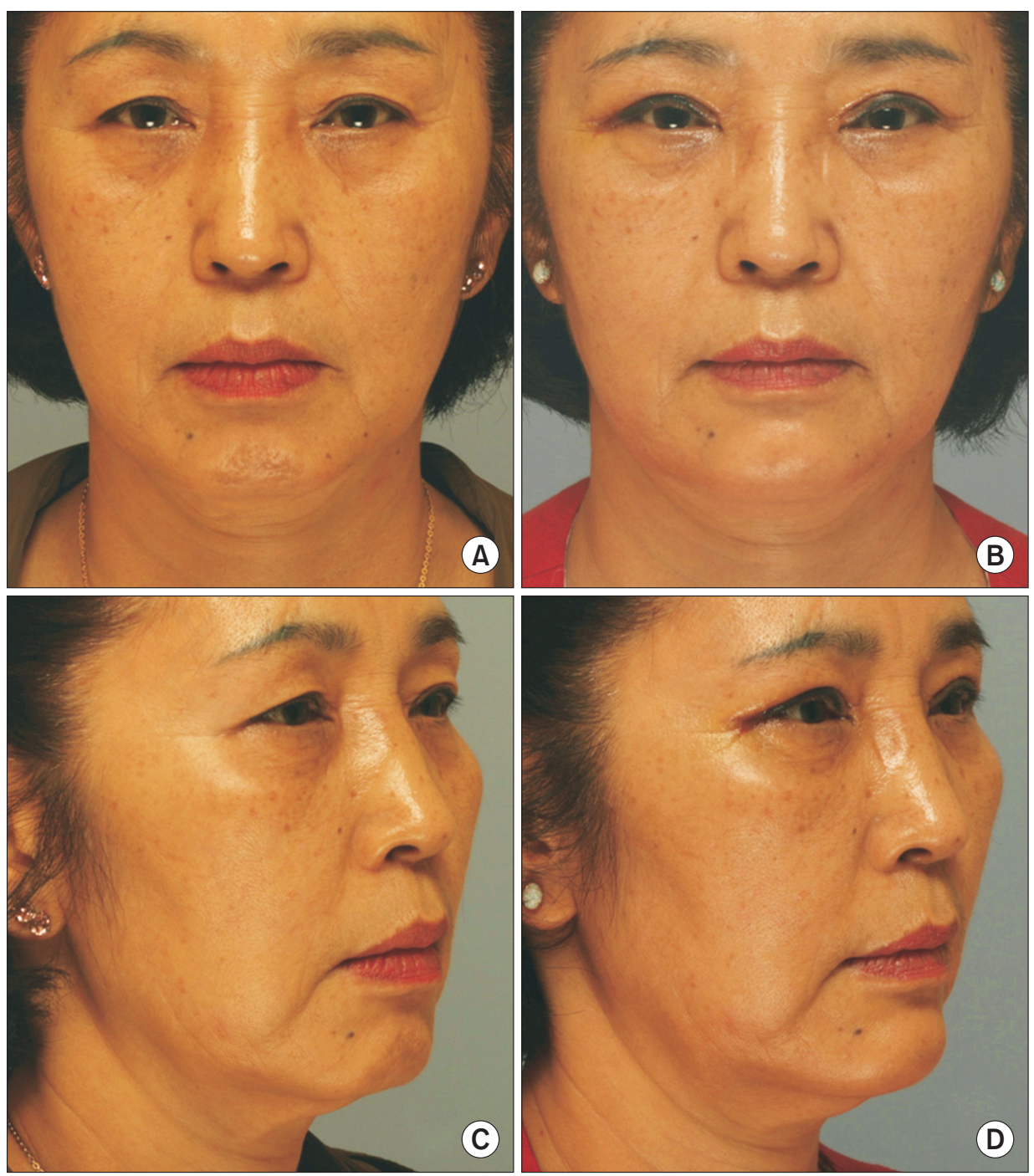

Fig. 4. Change of chin appearance 3 weeks after chin augmentation. (A) Before procedure, (B) 3 weeks after procedure. Filler and botulinum toxin were injected into a 60 -year-old woman who had a small chin (12th case from Table 1 and 2).

resulting in the sagging of the soft tissues, while large and protruded bones provide strong skeletal support to the surrounding soft tissues, preventing sagging [11]. Therefore, the soft tissues on the small and flat bony mentum receive poor skeletal support, and in terms of the mentalis muscle in relaxation, the soft tissues of the chin, including the lower lip, sagged and eventually resulted in incomplete mouth closure. In order to avoid this, patients usually will contract the mentalis muscle to close their mouths and it is at this time that the mouth appears to protrude as bunching and pouting with the appearance of the mentalis dimple. In this kind of situation, if the filler is injected into the subdermal, intramuscular, submuscular, and supraperiosteal layers, it induces poor skeletal support and not only increases chin ptosis but also causes the injected filler to migrate from the injection site, gathering into bumps, lumps, or nodules beneath the skin because of bunching and pouting due to continuous mentalis contraction [12].

In this study, there were no complications such as chin ptosis and vascular occlusion as shown in Table 5. We used six entry sites and attempted to correct the asymmetric chin by injecting different amounts of the filler into each site. However, in the area of mental dimpling where the amount of soft tissue significantly decreased before the procedure, an uneven surface occurred in two cases and it was the main cause of the asymmetry. This was corrected by injecting a small amount of filler into the subdermal and submuscular layers.

The purpose of this study was not to increase the volume of the soft tissues of the chin but to correct the bony deformity of the small and flat mentum through subperiosteal injection and eventually increase the skeletal support provided to the soft tissues. Marked improvements were noted as mentioned above and additionally, the incidence of complications was decreased. 

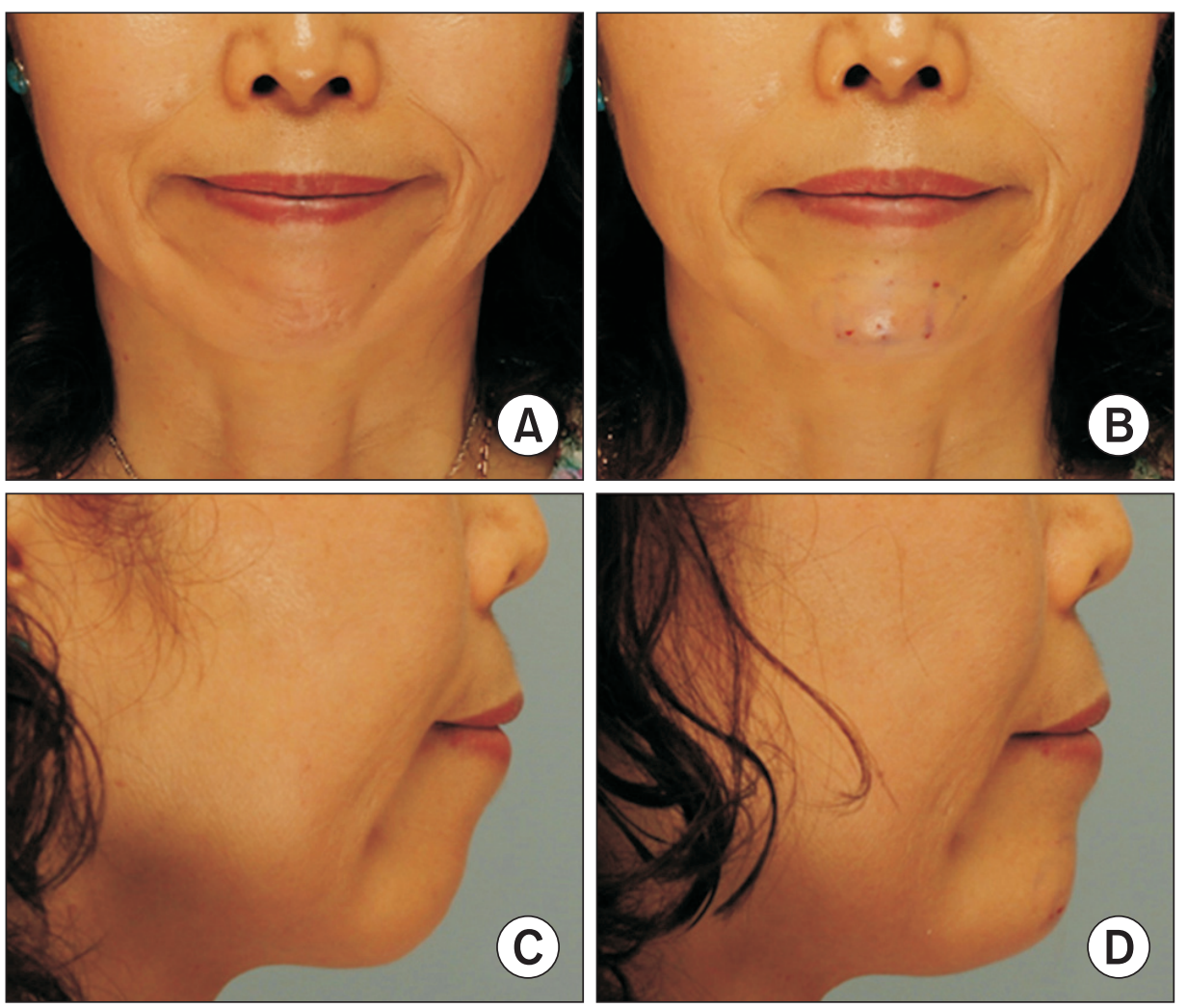

Fig. 5. Immediate change of perioral animation after filler injection. Filler was injected into a 52-year-old woman who had a small chin (9th case from Table 1 and 2). (A) and (C) Before procedure, (B) and (D) Immediately after procedure.

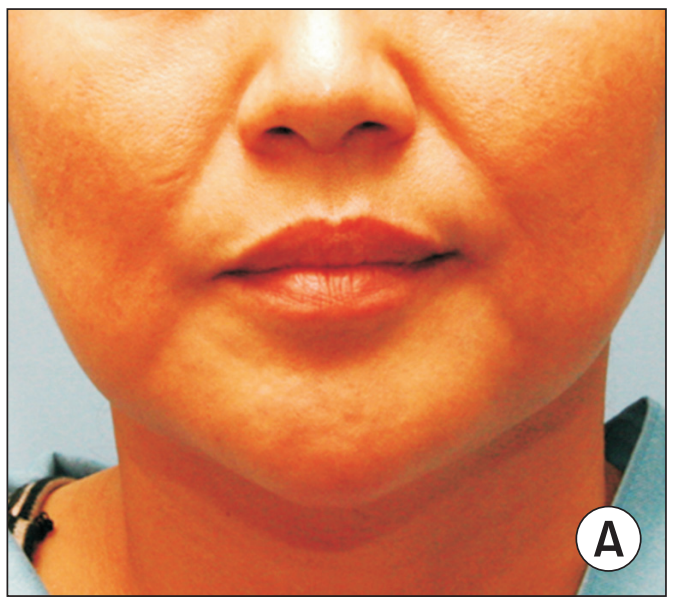

\section{Conclusion}

Subperiosteal filler injection is a noteworthy alternative for the correction of the small chin without chin ptosis. Moreover, its additional benefits, such as the improvement of dry mouth, lips contour, and perioral wrinkles are attributed to the increased skeletal support for the soft tissues of the lower lip and chin by the subperiosteal placement of the filler.

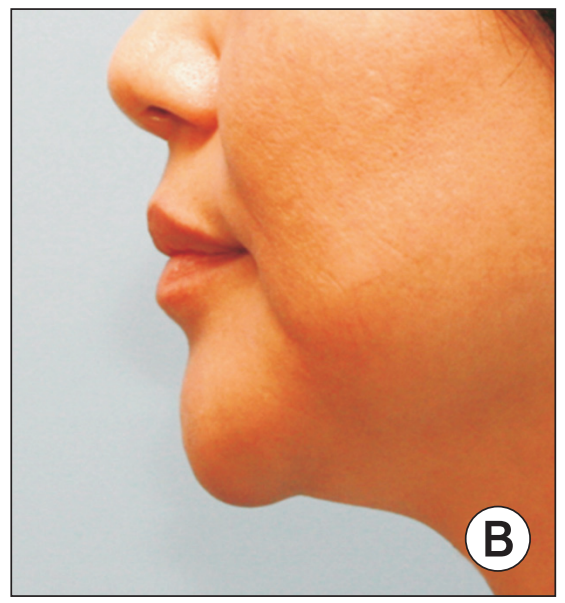

Fig. 6. A complication case characterized by tiny multiple nodules, mental dimples, asymmetry, and chin ptosis occurred to the patient, who has been injected man-made filler into intradermal, subcutaneous, and submuscular layers. (A) Frontal view, (B) Lateral view.

\section{Acknowledgments}

Our sincere gratitude goes to Park Min-Su, Ph.D. who contributed to the quality improvement of this paper with appropriate and excellent statistical analysis.

\section{Conflicts of interest}

The authors have nothing to disclose. 


\section{References}

1. Kang KJ. SAFI (Sequential autologous fat injection). Seoul: Koonja Publishing Inc.; 2017. p. 234-36.

2. Bertossi D, Galzignato PF, Albanese M, Botti C, Botti G, Nocini PF. Chin microgenia: a clinical comparative study. Aesthetic Plast Surg 2015;39:651-8.

3. Bass LS. Injectable filler techniques for facial rejuvenation, volumization, and augmentation. Facial Plast Surg Clin North Am 2015;23:479-88.

4. Rho NK, Chang YY, Chao YY, Furuyama N, Huang PY, Kerscher $\mathrm{M}$, et al. Consensus recommendations for optimal augmentation of the Asian face with hyaluronic acid and calcium hydroxylapatite fillers. Plast Reconstr Surg 2015;136:940-56.

5. Garfein ES, Zide BM. Chin ptosis: classification, anatomy, and correction. Craniomaxillofac Trauma Reconstr 2008;1:1-14.

6. Mendelson B, Wong $\mathrm{CH}$. Changes in the facial skeleton with aging: implications and clinical applications in facial rejuvenation. Aesthetic Plast Surg 2012;36:753-60.
7. Rohrich RJ, Pessa JE. Discussion. Aging of the facial skeleton: aesthetic implications and rejuvenation strategies. Plast Reconstr Surg 2011;127:384-5.

8. Shaw RB Jr, Katzel EB, Koltz PF, Yaremchuk MJ, Girotto JA, Kahn DM, et al. Aging of the facial skeleton: aesthetic implications and rejuvenation strategies. Plast Reconstr Surg 2011;127:374-83.

9. Carruthers J, Fagien S, Matarasso SL; Botox Consensus Group. Consensus recommendations on the use of botulinum toxin type a in facial aesthetics. Plast Reconstr Surg 2004;114(6 Suppl):1S-22S.

10. Arroyo HH, Olivetti IP, Lima LF, Jurado JR. Clinical evaluation for chin augmentation: literature review and algorithm proposal. Braz J Otorhinolaryngol 2016;82:596-601.

11. Kang KJ. SAFI (Sequential autologous fat injection). Seoul: Koonja Publishing Inc.; 2017. p. 71-6.

12. Belmontesi M, Grover R, Verpaele A. Transdermal injection of Restylane SubQ for aesthetic contouring of the cheeks, chin, and mandible. Aesthet Surg J 2006;26(1S):S28-34. 